\title{
CARTEIRA ROSA:
}

\section{A TECNOFABRICAÇÃO DOS CORPOS SEXUADOS NOS TESTES DE FEMINILIDADE NA OLÍMPIADA DE 1968}

\author{
DRA. PATRÍCIA LESSA
}

Professora titular do Departamento de Fundamentos da Educação Universidade Estadual de Maringá (UEM/PR), Doutora pelo Programa de Pós-Graduação em História (UnB/DF); Realizou Estágio Pós-Doutorado na Universidade Federal Fluminense no Programa de Pós-Graduação em Letras

(UFF/RJ), sob supervisão do Dr. Sebastião Votre (Maringá - Paraná - Brasil)

E-mail: mafalda_cat@yahoo.com.br

\section{DR. SEBASTIÃO JOSUÉ VOTRE}

Professor titular do Programa de Pós-Graduação em Educação Física da Universidade Gama Filho (UGF/RJ); Doutorado em Linguística Aplicada pela Pontifícia Universidade Católica do Rio de Janeiro; Pós-Doutorado em Sociologia do Esporte, na Universidade de Strathclyde (Escócia); Pós-Doutorado em Linguística pela Universidade de Laval (Canadá) (Rio de Janeiro - Rio de Janeiro - Brasil)

E-mail: sebastianovotre@yahoo.com

\section{RESUMO}

Sexo e gênero tomam uma nova forma após a descoberta científica dos hormônios. Inicia um período de investimentos tecnológicos e políticos que culminam na manipulação artificial dos hormônios, assimilados pelo doping esportivo para melhoria das performances. Com o doping surge a preocupação em comprovar o gênero das atletas mulheres. A Olimpíada de 1968 foi um marco no início dos testes de feminilidade. Esse estudo investigou os discursos dos jornais da época sobre as condições políticas que levam aos testes, caracteriza-se por uma pesquisa histórica documental. Nossas fontes foram o Jornal dos Sports e o Jornal do Brasil, o período analisado foi o segundo semestre de 1968. Foram utilizadas as Teorias Feministas Contemporâneas para o diálogo com as fontes primárias.

PALAVRAS-CHAVE: Carteira rosa; Jogos Olímpicos; feminilidade; corpo. 


\section{INTRODUÇÃO: RUMO À SOCIEDADE MEDICALIZADA, À DESCOBERTA DOS HORMÔNIOS E SEUS USOS NOS ESPORTES}

As concepções de sexo e gênero não seriam mais as mesmas após a manipulação dos hormônios sintéticos. Com as fronteiras de gênero rompidas, a tecnofabricação dos corpos sexuados alavanca uma das indústrias de maior crescimento nas últimas décadas: a indústria farmacêutica. A partir de então o gênero pode ser modificado, configurando uma nova corporeidade medicalizada e remodelada via procedimentos cirúrgicos. A criação e a manipulação dos hormônios sintéticos consolidam a tecnofabricação dos corpos sexuados. Utilizamos a ideia de tecnocorpos de Preciado (2008), que incorpora a tecnologia tematizada por Haraway ( 1994) e a discute tendo como foco a indústria farmacoquímica, assim, preferimos o termo tecnobiopoder ao biopoder foucaultiano, pois não se trata somente do poder sobre a vida, mas também do poder e controle sobre todo o tecnovivo, conectado, midiatizado, transformado em vetor de replicação. Nesse novo contexto, ciência e tecnologia são aliadas na construção dos corpos sexuados, mantendo ou reinstituindo a divisão do mundo em dois gêneros assimétricos.

As pesquisas dos anos 1960 procuravam comprovar que os hormônios sexuais têm uma estrutura química relacional, observando-se que em vários tecidos de ambos os gêneros o colesterol é metabolizado em progesterona a qual se metaboliza em testosterona. Em alguns estudos com animais tentava-se relacionar agressividade com maior quantidade de testosterona no organismo. Nos termos de Rodrigues (2004, p. I l0):

Esto dió lugar a investigaciones em las que se pretendió probar la existencia de una relación causal entre niveles de andróginos (sobre todo testosterona) proprios del sexo masculino y la agresividad.

O que as pesquisas não levavam em consideração na época eram as condições de cativeiro em que os animais estudados eram mantidos, embora o contexto fosse uma variável que deveria ser controlada. Um dos resultados dessas pesquisas foi a fabricação e divulgação dos hormônios sintéticos colaborando para o distanciamento entre os gêneros, reduzidos a códigos genéticos e taxas hormonais.

A descrição técnica do uso da testosterona pressupõe que o usuário seja um homem que não produz naturalmente uma quantidade suficiente de andrógenos, tal uso implica que esse usuário é heterossexual, pois relaciona a parceira sexual como mulher. Isso porque a noção de homem faz referência à definição cromossômica XY, genital, que possui pênis e testículos ou, definição legal, que menciona homem na carteira de identidade. Portanto, é mandatário não se identificar como mulher para 
obter legalmente uma dose de testosterona, embora o produto seja comercializado no mercado negro e facilmente encontrado na internet. É exatamente essa relação hormônio-gênero que é virulentamente criticada como nova produtora dos corpos sexuados. Na história da sexualidade foucaultiana, o que eram práticas sexuais se converte em identidades, em condições políticas a serem estudadas, catalogadas, perseguidas ou curadas. Cada corpo representa um indivíduo que eventualmente é necessário corrigir. Por exemplo, a mulher barbada, na nova epistemo-sexualidade se converte em objeto de investigação para aferir os níveis de testosterona numa fêmea ou então vira um espetáculo circense, de todo modo, ela é reduzida a aberração. Nesse quadro conturbado, as atletas tornam-se alvo de políticas de monitoramento, controle e vigilância sobre seus corpos.

Com o surgimento e a expansão da indústria farmacoquímica, os esportes femininos dão um salto na virada dos anos 1960. A testosterona sintética desde então tem sido usada em grande escala nos esportes. Esteróides e anabolizantes fizeram uma grande diferença nas performances e recordes desde então. Nos anos 1960, a Alemanha saiu na frente em campeonatos internacionais femininos de natação e atletismo, utilizando, entre outros recursos, o uso indiscriminado de drogas (DEVIDE; VOTRE, 2005). O impacto da indústria foi imediato. Com o avanço das pesquisas nas áreas de bioquímica, endocrinologia e genética criou-se uma política internacional de manipulação hormonal, sendo o campo desportivo um exemplo para tais investimentos tecnológicos.

O contexto singular da época oferecia condições ideais para a produção dos hormônios sintéticos, pois se vivia num cenário político de "revoluções": movimentos feministas, ecológicos, estudantis, negros, etc, que marcaram as conflituosas décadas de 1960 e 1970. Nesse período particularmente conturbado, novas formas de eugenismo associam-se a interesses econômicos e políticos internacionais de lutas anticomunistas e antifeministas, era o auge da chamada "guerra dos sexos". No campo dos megaeventos esportivos, a época teve a realização da XIX Olimpíada.

Essa turbulência social e econômica é uma das marcas da Olimpíada de 1968, a primeira a realizar-se na América Latina, após disputa da escolha do local com países como a França e os Estados Unidos. Na semana que antecedeu a XIX Olimpíada, os jornais noticiaram uma matança de estudantes na praça central da Cidade do México, gerando uma mobilização de estudantes de diversos países, principalmente da Itália e França, que argumentavam a favor do cancelamento do evento (TRONCOSO, 2008). Sob vários protestos, a Olimpíada iniciou-se sem a presença de alguns países, entre eles a Coreia do Norte, pois o Comitê Olímpico Internacional (COI) não a reconheceu como República Democrática da Coreia (JB, I5/10/68b, p. 20). 
A Olimpíada se caracterizava, no quesito saúde, pela participação de um comitê médico, sob cuja orientação se iniciaram os testes de feminilidade, também divulgados como: testes de gênero e testes de sexo, que conferiam às atletas consideradas aptas a carteira rosa. Esse documento era uma espécie de passaporte para as mulheres participarem dos Jogos Olímpicos, com a comprovação científica de que elas eram efetivamente mulheres. Reduzidas à equação $X X$, somente assim elas poderiam participar de Jogos oficialmente organizados pelo $\mathrm{COI}$.

A participação das mulheres nos Jogos Olímpicos segue uma trajetória de rejeições e controles, desde o início desses jogos na era moderna. Na primeira edição dos Jogos Olímpicos em I896, em Atenas, na Grécia, as mulheres não participaram, segundo as ideias e os preceitos do Barão Pierre de Coubertin, para quem as mulheres não teriam capacidade física para suportar as provas. Seguindo os preceitos do mestre, o COI impôs barreiras à participação feminina, que foram sendo enfraquecidas ao longo de sua história. Desde os Jogos de Berlin em 1936 , na era de Hitler, as suspeitas de "feminilidade duvidosa" fazem parte da história da participação feminina nos esportes olímpicos. Escândalos olímpicos foram selecionados e utilizados nesse sentido. Uma corredora tcheca, de 1930, chamada Zend Koubrova, viu uma fotografia de seus genitais ambíguos publicados. Ela retornou para sua casa e assim permaneceu reclusa por anos. Vários são os exemplos de humilhação pública e desconforto com relação aos testes.

Na II ${ }^{a}$ edição dos Jogos na Cidade de Berlim na Alemanha em 1936, a americana Helen Stephens ganhou na prova dos 100m da atleta já conceituada na época: Stella Wash, que, embora não tenha ficado em primeiro lugar, era famosa e foi alvo da mídia, na ocasião foi acusada de ser um homem por um jornalista que fazia cobertura do evento. Os médicos germânicos inspecionaram seus genitais e concluíram que ela era uma mulher. Isto pôs fim ao debate, mesmo com crenças de que outras corredoras "corriam como homens". Nos anos 1980, Stella Wash foi morta durante um roubo e a autópsia mostrou que era ela que tinha genitais masculinos e femininos.

Nos anos 1960, quando a cobertura televisiva das olimpíadas começou, expectadores viram mulheres ganharem medalhas olímpicas, dando início às polêmicas de que muitas das atletas que competiam seriam homens passando-se por mulheres. Em 1966, os testes de feminilidade foram introduzidos durante a reunião do COl: atletas femininas eram postas nuas e submetidas a exames ginecológicos (COI, 1997). Em 1968 o COI introduziu o teste de feminilidade para substituir os exames ginecológicos por uma "verificação científica", para saber se cada competidora possuía os dois $X X$ através dos cromossomos. 
A partir da Olimpíada de 1968, para muitas atletas femininas, as semanas que antecediam os jogos se transformavam num período de terror. Várias dessas muIheres tinham medo de não passarem no teste de feminilidade e de serem expostas ao mundo como homens. A reação não se fez esperar e os testes de feminilidade foram perdendo credibilidade e sendo questionados pelas próprias atletas, que começaram a se organizar em ligas femininas.

Nas seções a seguir procederemos à análise de alguns casos divulgados na mídia, para interpretar a dinâmica da carteira rosa e questionar seus pressupostos, a partir do diálogo com as Teorias Feministas Contemporâneas e da análise dos jornais de 1968, relacionando-os às questões políticas e culturais do período.

\section{CARTEIRA ROSA: UMA PROPOSTA DE ESTUDO DA FEMINILIDADE DUVIDOSA}

A preocupação com o controle de doping nos esportes surge na mesma época dos exames de verificação de sexo implantado pelo COI nos Jogos Olímpicos de 1968, no México, que deixaram de ser obrigatórios após a edição de 2000, em Sydney. O COI divulgou, em reunião em 1999 (ABOLIDO, 25/07/1999, p. 2), que iria rever o regulamento e, desde a Olimpíada de 2004 em Atenas, eles só são realizados em casos excepcionais. As provas de feminilidade, realizadas desde 1948 através de fotografia e verificação das genitálias, tomaram diversas formas nas últimas décadas. Em vista de várias fotografias de genitália vazadas para a imprensa internacional, terem causado constrangimento nas mulheres atletas, a política desportiva internacional passou a adotar o exame sanguíneo e genético. Entretanto, por ser considerado pouco confiável, esse teste foi abandonado pela Federação de Atletismo Internacional (IAAF) em 1992, e os casos suspeitos passaram a ser analisados por um grupo de "peritos em medicina desportiva" do COI. A verificação de sexo ganhou contornos mais agudos com o advento do uso "científico" dos testes de cromossomo, passando a constituir etapa obrigatória para ingresso nos Jogos. Mesmo antes desse teste, o monitoramento sobre os corpos femininos é uma prática generalizada no universo do esporte de rendimento, confirmando Hargreaves (2000), para quem o esporte exclui as mulheres à medida que constitui-se enquanto espaço de poder dos homens, uns sobre os outros e de todos sobre as mulheres. As diferenças sexuais passam a ser interpretadas como diferenças de gênero. Quando as mulheres começaram a sobressair nos esportes de rendimento, principalmente as soviéticas e alemãs, recrudesceram os questionamentos sobre seu porte, suas "características masculinas", e elas passaram a ser questionadas quanto à sua identidade de gênero (DEVIDE, 2005). Como força, velocidade e agressividade 
são atributos relacionados ao gênero masculino, cria-se uma confusão quando determinantes sociais são reduzidos ao determinismo biológico. As mulheres seriam fracas por natureza hormonal, e, por conseguinte, as mulheres fortes deveriam ser homens disfarçados de fêmeas.

O mais recente caso divulgado na mídia foi da velocista sul-africana Caster Semenya, campeã mundial dos $800 \mathrm{~m}$ rasos, que declarou à imprensa internacional encarar como piada a polêmica em relação a sua feminilidade. Anna Kessel (20 l 0) escreveu, para o jornal Guardian, que a atleta estava, na ocasião, indignada com o debate sobre seu gênero. A perseguição contra a atleta levou-a a uma entrevista na revista sul-africana You, na qual ela aparece na capa, maquiada, usando um vestido e alguns acessórios femininos, adornos socialmente articulados ao gênero feminino. Ela encenou uma performance de gênero ao sabor da pedagogia da aparência, na qual o que conta são os acessórios, os modos, os trajes, os comportamentos que marquem o gênero como socialmente e culturalmente dados (BUTLER, 2003). A atleta fez coro ao que se vem fazendo, ao longo da história, com as mulheres atletas, ora se anulando, ora criando mecanismos para debochar e burlar as regras que as excluem dos esportes (HARGREAVES, 2000).

Os testes inicialmente eram visuais, incluindo fotografias dos genitais. A partir da Olimpíada do México vieram os testes de cromossomo, e as atletas que não passavam nos testes de feminilidade eram, em alguns casos, banidas, e, mais recentemente, já na década de 1990, impelidas a buscarem tratamentos hormonais e, se necessário, cirurgias de redesignação do sexo, que servem para ajustar sexo e gênero.

Uma das áreas biotecnológicas de avanço expressivo nos últimos anos diz respeito às possibilidades de intervenção, no que se refere à 'redefinição do sexo', em crianças e adultos. Portanto, as questões em torno da sexualidade, já de longa data, esfera privilegiada das prescrições médicas e psicológicas, retornam com toda sua força nas decisões estabelecidas em um contexto social específico - o hospital - quando o assunto é a 'construção do sexo'. A primeira cirurgia de redesignação sexual oficialmente comunicada aconteceu em 1952, na Dinamarca (CHILAND, 2008). Desde aquela época avançam as intervenções cirúrgicas para mudança, re-designação ou readequação do sexo.

O movimento de construção deu força à emergência dos 'estados interssexuais' que se referem, de forma geral, a corpos de crianças nascidas com a genitália externa e/ou interna nem claramente feminina, nem claramente masculina (CHILAND, 2008). De acordo com a literatura médica, essas pessoas podem ser divididas em quatro grupos principais: pseudo-hermafroditismo feminino (o bebê possui ovário, o sexo cromossômico é $46 \times X$, a genitália interna é feminina, mas a 
genitália externa é 'ambígua'); pseudo-hermafroditismo masculino (a criança possui testículos, cariótipo 46 XY, mas a genitália externa é 'feminina' ou ambígua); disgenesia gonadal mista (o bebê nasce com gônadas disgenéticas); hermafroditismo verdadeiro (crianças que possuem tecido ovariano e testículos na mesma gônada ou separadamente) (ARAN, 2006). As pesquisas demonstraram que o cromossomo Y podia ser observado em pessoas portadoras de órgãos sexuais femininos. Muitos casos foram observados - tais como $X X X, X X Y, X Y Y$ - acompanhados ou não de anomalias genitais (HILAIRE, 2000).

A suposta 'ambiguidade' dos genitais reforça e impulsiona, do ponto de vista médico, a busca por elementos que esclareçam o 'mistério' da diferenciação sexual. Com isso, a verdade sobre o sexo pode assumir desde formas mais simplificadas (como 'XY é homem' e ' $X X$ é mulher') até formas mais elásticas e de profunda complexidade. Deve-se levar em conta, também, o argumento de que a presença de $X Y$ e de testículo são determinantes para que um menino se reconheça como tal, e também o posicionamento de que tudo isso informa, mas não é o sinal determinante para uma criança ou para os seus pais (HILAIRE, 2000).

Na discussão de corpo empreendida por Butler (2003) destaca-se a impossibilidade de olhar para o sexo sem que seja a partir do gênero, o que faz com que o sexo se constitua, desde sempre, como generificado. Ele não é menos cultural ou mais natural que o próprio gênero. Nessa linha de raciocínio, pensar a temática da 'genitália ambígua' e a percepção médica dos genitais, é entender que o gênero é uma prática que é reafirmada no social e que faz com que seja possível 'olhar' um corpo de menina ou de menino.

Os testes de feminilidade duraram oito edições dos Jogos Olímpicos, de 1968 até 2000. Porque duraram mais de três décadas, mesmo diante das críticas, tanto de associações e entidades médicas e científicas, como da imprensa e das próprias atletas? Essa medida e sua duração podem ser vistas como barreira à participação feminina e, também, como uma forma de mascarar que o doping assumiu proporções incontroláveis com o advento da indústria farmacoquímica?

A polonesa Eva Kobkowsca foi banida dos eventos femininos em 1967 por ter cromossomos XXY. No Brasil, dois casos ganharam visibilidade na mídia nacional. No judô, em 1996, houve a polêmica em torno de Edinanci Silva, e no vôlei, em 1997, em torno de Érika Coimbra. Elas nasceram mulheres, mas tiveram a sexualidade contestada porque apresentavam características de ambos os sexos, excesso de hormônio masculino e precisaram passar por cirurgias reparadoras para competirem como mulheres. Érika, jogadora da seleção brasileira, foi submetida ao exame durante o mundial juvenil, em setembro de 1997, e teve o resultado positivo. Ela tinha uma má formação dos órgãos reprodutores e teve de ser submetida a uma cirurgia e a 
tratamento hormonal. Na época, o mexicano Ruben Acosta, presidente da Federação Internacional de Voleibol (FIV), obrigou o Brasil a tirar Érika da competição, sob ameaça de a equipe ser eliminada do torneio. Acosta mostrou-se à imprensa como conservador, e afirmou que a "sua entidade" não seguiria a medida anunciada pelo $\mathrm{COI}$ de abrir as portas das competições para as transexuais. Ele declarou publicamente que permitir a presença de mulheres transsexuais em torneios de vôlei é abuso humano. No início de 2005, a FIV decidiu abolir testes de feminilidade (RAMOS, 1998). Os testes nunca provaram que um homem foi mascarado como mulher, mas, certamente, ridicularizaram publicamente as mulheres interssexuais.

Em 15 de maio de 2004, o COI decidiu divulgar as regras estabelecidas para que as transsexuais e os interssex pudessem participar dos Jogos. Tal decisão suscita algumas questões. Essa medida não seria mais um vestígio de que a ciência foi obrigada a reconhecer que o gênero não é absoluto? Essa não seria uma forma de assumir o doping como uma prática do esporte de rendimento? Pois os métodos para a transsexualidade consistem na introdução de substâncias no corpo. Ora, como o hormônio sintético é central, sua introdução poderia caracterizar-se como um procedimento análogo ao doping. No entendimento médico, transsexuais são pessoas que possuem o gênero cerebral oposto aos genitais, e, para a correção, recorre-se a medidas cirúrgicas, hormonais e medicamentosas. As pessoas transsexuais que podem participar são apenas as que querem passar do masculino para o feminino, pois o inverso ainda não é permitido, entende-se com isso que as muIheres continuam sendo reduzidas à esfera biológica, ancoradas em uma natureza fraca e imutável.

Em termos gerais, é lícito concluir que os Jogos Olímpicos de 1968 dão início a um processo de monitoramento, catalogação e normatização dos corpos femininos. Tal processo emerge justamente em um período da história em que movimentos sociais questionam a ordem hierarquizada e binarizada do mundo. Dadas as condições e o contexto cultural e político dessa edição dos jogos, este estudo objetivou analisar os discursos dos jornais da época sobre as condições políticas que favoreceram a realização dos testes de feminilidade. $\bigcirc$ presente trabalho se caracteriza como pesquisa documental, o corpus reúne matérias e reportagens da época em questão. Nossas fontes foram: o Jornal dos Sports (JS), mais relacionado a questões esportivas, e o Jornal do Brasil (JB), de escopo mais amplo. O período analisado é o segundo semestre de 1968. A seção selecionada, em ambos os periódicos, era dedicada aos jogos, em edição especial separada das demais notícias desportivas da época.

As questões que nortearam esta pesquisa são: qual cenário político para as condições de produção dos testes de feminilidade? Como o doping esportivo e os 
testes de feminilidade podem ser relacionados a questões políticas? Nossa hipótese é de que no período em estudo, marcado pelo anticomunismo, pelo antifeminismo e pela guerra dos sexos, o teste de feminilidade se mostra como mais um instrumento a serviço da divisão binária e hierarquizada dos gêneros, como mais uma barreira imposta às mulheres atletas. A cada tentativa institucionalizada de comprovação da feminilidade, verifica-se a complexidade da sexualidade humana. A desconstrução de gênero se faz presente mesmo na tentativa de enquadrá-la, submetê-las às normas e ditames da heteronormatividade.

\section{A XIX OLIMPÍADA DO MÉXICO: ADEQUAÇÃO BIOMÉDICA PARA AS MULHERES ASCENDEREM AO ESPORTE DE RENDIMENTO}

A XIX Olimpíada foi realizada no México, primeira vez na América Latina, e teve início no dia 12 de outubro de 1968. Os jornais da época anunciavam um contexto político de revoltas estudantis e protestos de várias ordens, na Europa e nas Américas. Críticas contra o racismo e o machismo tornaram-se presentes na voz de ativistas sociais. $\bigcirc \mathrm{CO}$ era então uma importante instituição desportiva internacional e, também, foi alvo de críticas pela postura conservadora e muitas vezes antiética, principalmente no que tange aos negros, aos atletas homens e mulheres de países socialistas e às mulheres em geral.

O presidente do $\mathrm{COI}$ na ocasião dos Jogos no México era um norte-americano, fã declarado de Hitler, então com 81 anos de idade. Avery Brundage era frequentador de um clube de bridge em Chicago que proibia a entrada de negros e judeus, e segundo Máximo (1968, p. 18), tinha um painel na entrada onde se lia: "Jews and Negros no admittance". Seus discursos e declarações aos jornalistas refletiam essa postura conservadora. Quanto aos protestos estudantis ele disse à imprensa: "Não vejo hippies e beatniks nos estádios, daí eu achar que toda intolerância dos jovens de hoje se deve ao fato de que eles não praticam esportes" (MÁXIMO, 1968, p. 18). Essa resposta e consequente atitude do presidente do COI diante da polêmica que tomou grandes proporções na semana que antecedeu o início dos jogos, levou vários estudantes à morte e muitos outros a prisões deliberadas. As autoridades locais reagiram ao movimento, alegando que era resultado da rebelião comunista organizada por entidades internacionais para boicotar as Olimpíadas (TRONCOSO, 2008).

Suas declarações representam uma negação total dos fatos políticos que estavam ocorrendo, das mobilizações estudantis contra o planejamento dos programas de estudos, contra o autoritarismo dos governantes, contra a falta de liberdade, tanto na vida política quanto cultural, aliada a protestos contra a guerra do Vietnã. 
Por outro lado, as declarações representam um ideário do esporte, como modo de adestramento da juventude rebelde, uma ideia que é retomada em muitos discursos presentes nas instituições desportivas. Ele disse ainda: "o esporte foi feito para uma elite universal" (MÁXIMO, 1968, p. 18). Entendemos que essa elite universal seria para ele composta por jovens alienados da cultura e da política.

A imprensa da época não deixou de mostrar as críticas e descontentamentos com o preconceito racial, que eram veiculados nas reportagens: "graças à excessiva preocupação dos americanos em estabelecer percentuais exatos de sangue puro em homens mestiços, Thorpe perdeu as medalhas porque era 'meio índio' meio branco'" (JB, 19/10/68e, p. 18).

Os jornais estavam atentos a crise que se avolumava. Uma reunião da Comissão Executiva aconteceu entre os dias 7 e II de outubro de 1968, para a reorganização do COI. Na pauta, constava a questão das "associações paralelas", vistas como "paralelismo perigoso" (JB, 0I//0/68c, p. 22). Para os detentores do poder, descentralizar o poder do $\mathrm{COI}$ podia ser interpretado como meio de entrada dos comunistas, dos negros e todo tipo de gente que ameaçava o poder da instituição. $\bigcirc$ JB era explícito:

\footnotetext{
Repercute no mundo inteiro a reeleição de Avery Brundage à presidencia do Comitê Olímpico Internacional. Simpatizante do antigo regime nazista, membro de um clube que não admite sócios negros e judeus, defensor por omissão do apartheid sul-africano e racista em seu próprio país, Brundage é visto, por uma ala renovadora do esporte mundial, como um nome do passado. O Times, de Londres, em sua edição de domingo, refere-se violentamente ao brundagismo, "organismo que dirige os Jogos e é composto por homens endinheirados e bem nascidos" (JB, I5/I0/68d, p. 20).
}

A notícia da reeleição do conservador Brundage não foi bem aceita no mundo. As questões raciais foram cruciais para a crítica na época, pois a equipe norte-americana chegou ao México dividida, com os atletas negros e brancos formando duas equipes alojadas em diferentes locais. A pressão contra os negros levou Smith e Carlos, dois medalhistas, a realizarem um protesto:

\footnotetext{
Dois atletas negros americanos ouro e bronze nos 200 metros receberam ontem um prazo de 48 horas para deixar a Vila Olímpica e voltarem aos Estados Unidos, por terem subido ao podium com luvas negras que representam seu protesto à segregação racial em seu país (JB, 01//0/68c, p. I8).
}

Eles perderam as medalhas, foram banidos e expulsos da vila olímpica, comprovando que a política vigente era repressora, agressiva e excludente, conformada com o ideário do presidente: o esporte olímpico é para uma elite, que pode ser 
entendida como um grupo seleto de pessoas a-politizadas ou então, conformadas com sua condição subalterna.

A África do Sul foi impedida de participar nessa edição. Se a repressão bateu forte nos negros, também foi muito dura com as mulheres, com o teste de comprovação de sexo. O Jornal dos Sports, na matéria intitulada: "Olimpíadas vencem a guerra dos sexos" anunciava a novidade com empolgação e aparência de imparcialidade:

A presença de indivíduos cujo sexo não pode ser perfeitamente definido nas provas femini-
nas das Olimpíadas está completamente banida e a prova é que muitos dos maiores atletas
que o mundo já viu ou não chegam ao México ou, lá chegados, se negaram a submeter-se
às provas para comprovação de sexo - disse ontem na redação do JS o Dr Aníbal Silva e
Costa, presidente da Sociedade Portuguesa de Medicina Esportiva. A obrigatoriedade dos
exames de sexo há muito tempo devia constar dos regulamentos olímpicos para evitar
a sobrevivência dos hermafroditas no esporte. Sempre fui a favor dos exames porque
existem mulheres que competem em tal categoria que na realidade são homens. Com a
obrigatoriedade dos exames, alguns fenômenos esportivos como as irmãs Irina e Tâmara
Press, da União Soviética, não compareceram ao México (OLIMPIADAS, 30/I 0/68, p. 5).

Não foi questionada a ausência de grandes nomes do esporte feminino de países comunistas, e sim deu-se destaque à dúvida sobre se essas atletas eram "mulheres de verdade". As irmãs Irina e Tâmara Press simbolizavam a rebeldia comunista, passível de crítica, como um alvo fácil, pois o mundo vivenciava a corrida anticomunista.

A pressão se dava contra as mulheres que fogem aos parâmetros, numa tentativa de reafirmar o mito de que haja uma mulher no singular, já que a ideia de uma mulher no singular, universal, é uma ficção, um mito criado para melhor disciplinar, melhor domesticar as mulheres reais, concretas. A esse respeito, Haraway (1994, p. 250) entende que "não há absolutamente nada a respeito de ser 'mulher' que aglutine naturalmente todas as mulheres". Questionando a categoria 'mulher', cabe interrogar sobre o sujeito político dos feminismos que, ao mesmo tempo, inauguram as mulheres como sujeitos/agentes e as desconstróem ao indicar os mecanismos de sua construção e de sua apropriação. Claro fica, entretanto, que, dos 'feminismos' nasceram 'as mulheres' e a consciência de sua instituição e representação como polo inferior do binário masculino/feminino, a serem desconstruídas. A análise prossegue cada vez mais rigorosa: "não há nem mesmo este estado de 'ser' mulher que é em si uma categoria altamente complexa construída nos discursos científicos sexuais e em outras práticas sociais" (HARAWAY, 1994, p. 250).

Na mesma página o jornal continua a matéria, agora com o subtítulo: "um exame simples": 
O exame para a comprovação de sexo - masculino ou feminino - é bastante simples e pode ser feito através de pesquisa de dois materiais: saliva ou sangue. Colhido o material, os cromossomos, são contados. Se atingir um índice $X$, morfologicamente a atleta é impedida de competir entre as mulheres, já que passa a ser considerada uma anomalia (O JOGO, 30/I0/68, p. 6).

A crença na ciência como detentora da verdade do sexo é uma representação ancorada no determinismo biológico. Pois costuma-se remeter ao biológico como critério para determinar o sexo dos indivíduos, sobretudo das mulheres. Contudo, podemos depreender dos estudos recentes que, mesmo a instância científica que poderia garantir de uma vez por todas a natureza da diferença sexual, oscila ao tentar fixar parâmetros (RODRíGUEZ, 2004). Nos excertos analisados encontramos indícios de que a fixação no feminino como natural soma-se à corrida anticomunista, conforme se registra no JS:

Não se pode afirmar taxativamente que os fenômenos que surgiram na Cortina de ferro, principalmente na União Soviética, fôssem homens ou hermafroditas. Entretanto é bastante sintomático que após a obrigatoriedade da verificação de sexo alguns dos fenômenos femininos não tenham comparecido ao México e, a par disso, a União Soviética tenha perdido a hegemonia no atletismo feminino, que mantinha há muitos anos (PORQUE, $31 / / 0 / 68$, p. 5).

A dúvida com relação às atletas da ala comunista é explícita, ou essas pessoas eram homens ou transsexuais, mas mulheres não poderiam ser, à medida que não eram iguais às "suas mulheres atletas". Diferenças culturais e políticas foram usadas com a maquiagem do teste, o que justifica a empolgação dos noticiários quanto à não presença das atletas oriundas do leste europeu. Assim como o JS, o JB anunciava a novidade: Médicos estabelecem normas para os Jogos,

A comissão médica designada pelo Comitê Olímpico Internacional estabeleceu ontem as normas definitivas dos trabalhos para emprêgo de estimulantes nos Jogos, assim como para a determinação do sexo (...) o exame de sexo será feito em atletas escolhidas - não se sabe se por sorteio - pela comissão (JB, I5//0/68a, p. 20).

Diante da notícia de que haveria regras taxativas contra o doping e contra mulheres com sexo duvidoso, a imprensa se mostrou complacente, pois a indeterminação do sexo soava como uma ameaça ao regime hetero-normativo. Qualquer anomalia deveria ser ou repelida ou recomposta. No curso dos Jogos, o JB publicou:

Sôbre a questão do contrôle de sexo, exigido pelo regulamento, o secretário geral Joanes Westterohff disse que a Federação Internacional de Natação foi a única que não respondeu oficialmente ao convite que lhe fêz o presidente da comissão médica para as nadadoras se 
submeterem à verificação sexual, apesar das nadadoras, em sua petição de inscrição, terem firmado o compromisso de se submeterem ao contrôle de sexo e contrôle sôbre o uso de drogas. $\bigcirc$ presidente da comissão de contrôle, Principe de Merod (Bélgica) afirmou que: 'caso uma atleta não se submeta ao contrôle sexual será excluída das competições'. O presidente da comissão médica acrescentou que várias atletas femininas inscritas nos Jogos já haviam aceito voluntariamente as exigências regulamentares" (JB, I5//0/68A, p. 22).

"Aceito voluntariamente as exigências" é uma contradição, pois se é uma exigência jamais será voluntária. Além disso, a rebelião das nadadoras é o indício de que o vínculo entre os testes e o doping era uma relação mais estreita do que se imaginava, pois a natação foi o esporte em que os casos de uso de substâncias químicas para melhoria da performance foram evidenciados em edições anteriores (DEVIDE; VOTRE, 2005).

Não seria mais fácil duvidar da "natureza do sexo" do que assumir que o doping era usado em grande escala? De todo modo, a barreira imposta às mulheres atletas foi remediada com uma "homem-nagem" (LESSA, 2005b). O JB anunciou: "Mexicana será a primeira mulher a levar a tocha olímpica". A atleta de nome Norma Enriqueta Basílio, campeã mexicana dos 80 metros com barreira, era a atleta escolhida para coroar o início dos jogos com a presença feminina,

Calipatira, filha, esposa e mãe de atletas, entrou no estádio, onde se disputavam os Jogos Olímpicos, disfarçada em treinador de seu filho que ia correr. Ao vê-lo vencer não se conteve: arremessou-se para abraça-lo, quando o manto lhe caiu. Esperava-se um castigo terrível: ser atirada do alto de um rochedo mas a multidão entusiasmada exigiu o seu perdão, concedido pelos juízes [...]. Na Grécia Antiga era assim: às mulheres não era permitido nem mesmo assistir os grandes jogos então celebrados: Olímpicos, Píticos, Ísticos, Istimicos e Nemeus [...]. Elas podiam realizar seus próprios jogos em hora e lugar diferentes, mas êsses nunca alcançaram destaque (DE CALIPATIRA, 02/I0/68, p. 20).

Recorrendo à mitologia grega, a narrativa pretendia explicar a exclusão histórica das mulheres, partindo do pressuposto de que existe uma história oficial e essa é a contada pelos homens, sobre os feitos e realizações dos homens. Uma história no plural, atenta às diferenças e marcada pelos conflitos e pelos debates feministas, se contrapõe a essa visão da história universal masculina. A história das mulheres, desse modo, é uma prática discursiva que nos possibilita buscar os sentidos expressos nos diferentes tipos de textos do passado, conscientes de que o fazem com o olhar e a interpretação do presente (GOELLNER, 2007; HARGREAVES, 2000). A guerra dos sexos volta à tona quando o jornal cita o livro: "Pedagogia Esportiva", de Coubertin, "O problema dos esportes femininos complica-se com a paixão e expressão exageradas que nêle põe a campanha feminista" (JB, 02/I 0/68b, p. 20). 
Os feminismos, tanto em suas ações como em suas teorias, vieram sacudir as evidências dos modelos totalitários de ser humano e, por isso, despertaram o medo e a repulsa do $\mathrm{COI}$, que tinha como meta identificar o verdadeiro sexo. Os Estudos Feministas são importantes em nossa pesquisa, na medida em que trazem um aporte teórico indispensável à análise e à construção do objeto de análise.

\section{CONSIDERAÇÕES FINAIS}

A imagem de uma mulher forte e atlética pode balançar a evidência do sexo e do gênero como norma catalogável. Antes da Olimpíada de 1968, o teste de sexo configurava-se numa anátomo-política. As mulheres expunham seus corpos nus a um comitê de "peritos", que julgavam e certificavam se sua morfologia era compatível com a feminilidade. Como tal prática significava uma invasão, uma exposição pública dos corpos das atletas, e vinha ganhando críticas das entidades esportivas, o comitê resolveu então "modernizar" os testes. A carteira rosa simbolizava feminilidade, a carteira era o passaporte das mulheres para o universo idílico de um feminino universal, naturalizado, e definido por uma equipe de peritos, composta por homens. $\bigcirc$ parâmetro genético adotado no teste de cromossomos indicava uma nova tecnobiopolítica de monitoramento e catalogação dos corpos femininos.

Para Preciado (2008) existe um regime farmacopornográfico, que subjaz à configuração do doping esportivo. A importância dada ao sexo só pode ser entendida à medida que se configura uma nova tecnologia de controle sobre os corpos e um novo investimento na verdade do sexo. Esse quadro leva a autora a postular que sexo está relacionado a uma rede de expressão do corpo sexualizado e ao universo das drogas e hormônios sintéticos, submetido ao tráfico internacional, camuflado no espírito esportivo de paz universal entre as nações.

Haraway ( 1994) recorre à imagem de seres "híbridos fabricados de máquinas e organismos", que manipulam seus destinos de acordo com os aparatos tecnológicos que estão ao seu dispor, com hábitos nos quais se potencializam as capacidades de interação e de performatividade. Interagem próteses comunicacionais e químicas, mapeamento do corpo em suas mínimas funções, otimização dos efeitos da alimentação, remoção de sintomas e de patologias, como indicadores desse imbricamento com a tecnologia. $\bigcirc$ doping nos esportes pode, nessa perspectiva, ser entendido como uma prótese química a serviço do espetáculo. O cyborg, personagem comum na ficção científica contemporânea, é utilizado por Haraway como metáfora para a crítica da identidade em favor das diferenças. Nos seus termos: "no final do século $X X$, nosso tempo, um tempo mítico somos todos quimeras, seres híbridos teorizados e fabricados ao mesmo tempo como máquina e organismo" (HARAWAY, 
1994, p. 284). No universo do esporte de rendimento esta maquinaria produtora de corpos e de novas subjetividades está em funcionamento há algum tempo é chegada a hora de encará-la.

A testosterona sintética não muda o sexo, mas o descodifica, modifica-o em seus afetos e percepções. Quando uma mulher inicia seus ciclos de testosterona, ela se perde na difusa área divisória dos gêneros, pois, nem é homem nem será 'a Mulher', no sentido que Wittig ( 1980 apud LESSA, 2005a) aborda, como uma semiótica dominante atrelada à subserviência e à dominação masculina. A testosterona é, portanto, dinamite para o regime heteronormativo e está aí sua periculosidade. Mulheres que se confundem com homens quebram o regime heterosexista e colocam a toda prova os limites na divisão binária do social.

\section{Pink Wallet: The Techno-making of Sexual Bodies in the Feminine Tests of the 1968 Olympics}

ABSTRACT: Sex and gender take a new shape after the scientific discovery of the hormones. It is the beginning of a period of technological and political investments that culminate in the artificial manipulation of hormones, which were assimilated by the sports doping to improve performance. Together with doping, there is the concern to prove the gender of the female athletes. The 1968 Olympics were a landmark in the early tests of femininity. This study, which is characterized as a historical documentary research, investigates the discourse of the newspapers of that time on the political conditions that lead to such tests. Our sources were the Sports Newspaper and the Brazil Newspaper, the period taken into account was the second half of 1968. The contemporary feminist theories were also used in order to keep a dialogue with the primary sources.

KEYWORDS: Pink wallet; Olympic games; femininity; bodies.

\section{Tarjeta rosada: la tecnofabricación de los cuerpos sexuados en los testeos de feminilidad en la Olimpiada de 1968}

RESUMEN: Sexo y género toman una nueva forma tras del descubrimiento científico de las hormonas. Inicia un período de inversiones tecnológicas y políticas que culminan en la manipulación artificial de las hormonas, asimiladas por el doping deportivo para la mejoría de las performances. Con el doping surge la preocupación por comprobar el género de las atletas mujeres. La Olimpiada de 1968 fue un hito en el inicio de los testeos de feminilidad. Ese estudio investigó los discursos de los periódicos de la época sobre las condiciones políticas que llevan a los testeos y se caracteriza como una investigación histórica documental. Las fuentes utilizadas fueron el Jornal dos Sports y el Jornal do Brasil y el período analizado fue el segundo semestre de 1968. Fueron utilizadas las Teorías Feministas Contemporáneas para el diálogo con las fuentes primarias.

PALABRAS CLAVE: Cartera rosa; Juegos Olímpicos; feminilidad; cuerpo. 


\section{REFERÊNCIAS}

ARAN, M. A transexualidade e a gramática normativa do sistema sexo-gênero. Ágora, Rio de Janeiro, v. 9, n. I, p. 49-63, jan./jun. 2006.

BUTLER, J. Problemas de gênero: feminismo e subversão da identidade. Rio de Janeiro: Civilização Brasileira, 2003.

CHILAND, C. O transexualismo. São Paulo: Loyola, 2008.

COMITÉ OLIMPICO INTERNACIONAL (COI). La mujer y el movimiento olímpico. In: SEMINARIO REGIONAL SOBRE MUJER Y DEPORTE, Caracas, 1997. Anais... Caracas: Departamiento de Cooperación Internacional, 1997.

DEVIDE, F. P. Gênero e mulheres no esporte: história das mulheres nos jogos olímpicos modernos. ljuí: Ed. da UNIJUI, 2005.

DEVIDE, F. P.; VOTRE, S. J. Doping e mulheres nos esportes. Revista Brasileira de Ciências do Esporte, Campinas, v. 27, n. I, p. 123-138, set. 2005.

GOELLNER, S. V. Mulheres, memórias e histórias: reflexões sobre o fazer historiográfico. In: GOELLNER, S. V.; JAEGER, A. A. (Org.). Garimpando memórias: esporte, educação física, lazer e dança. 2. ed. Porto Alegre: Ed. da UFRGS, 2007, p. I3-26.

HALBERSTAM, J. Masculinidad femenina. Espanha: Egales, 2008.

HARAWAY, D. Um manifesto para os cyborgs: ciência, tecnologia e feminismo socialista na década de 80. In: HOLLANDA, H. B. (Org.). Tendências e impasses: o feminismo como crítica da cultura. Rio de Janeiro: Rocco, 1994. p. 243-288.

HARGREAVES, J. Heroines of sport: the politics of difference and identity. London: Routledge, 2000.

HILAIRE, C. St. A dissolução das fronteiras do sexo. In: NAVARRO-SWAIN, T. (Org.). Textos de história. Brasília: Ed. da UnB, v.8, n. I/2, p. 85-। 12, 2000.

LESSA, P. Mulheres, corpo e esportes em uma perspectiva feminista. Motrivivência. Florianópolis: Ed. da, v. 17, n. 24, p. 157-172, jun. 2005.

Mulheres a venda. Londrina: EDUEL, 2005.

PRECIADO, B. Testo yonqui. Madrid: Espasa, 2008.

RODRIGUEZ, A. G. La estirpe maldita: la construcción de lo femenino. Madrid: Minerva, 2004.

TRONCOSO, A. C. O movimento estudantil de 1968 na cidade do México visto através da fotografia. Clio: série revista de pesquisa histórica, v. I , n. 26, v. I , 2008. Disponível em: $<$ http://www.ufpe.br/revistaclio/index.php/revista/article/viewFile/55/50>. Acesso em: 06 set. 2010 . 
FONTES JORNALISTICAS:

ABOLIDO TESTE DE FEMINILIDADE, Jornal a Noticia. Disponível em: <http://wwwl. an.com.br/I999/jul/25/esp.htm>. Acesso em: 26 set. 2010.

DE CALIPATIRA A NORMA. Jornal do Brasil. Rio de Janeiro, 2 out. 1968. p. 20. Caderno das Olimpíadas.

JORNAL DO BRASIL. Rio de Janeiro, I 5 out. 1968a, p. 20. Caderno das Olimpíadas.

JORNAL DO BRASIL. Rio de Janeiro, I 5 out. 1968b, p. 20. Caderno das Olimpíadas.

JORNAL DO BRASIL. Rio de Janeiro, 0 I out. 1968c, p. 22. Caderno das Olimpíadas.

JORNAL DO BRASIL. Rio de Janeiro, 15 out. 1968d, p. 20. Caderno das Olimpíadas.

JORNAL DO BRASIL. Rio de Janeiro, 19 out. 1968e, p. 18. Caderno das Olimpíadas.

KESSEL, A. Caster semenya third in Brussels $800 \mathrm{~m}$ as gender debate rages on. Disponível em: <http://www.guardian.co.uk/sport/caster-semenya>. Acesso em: ago. 2010.

MÁXIMO, J. O clube de "Mister" Brundage. Jornal do Brasil. Rio de Janeiro, 19 out. 1968 , p. 18. Caderno das Olimpíadas.

OLIMPIADAS VENCEM A GUERRA DOS SEXOS. Jornal dos Sports. Rio de Janeiro, Rio de Janeiro, 30 out. 1968, p. 5. Especial Olimpíadas.

O JOGO FORA DAS REGRAS. Jornal dos Sports, Rio de Janeiro, 30 out 1968, p. 6. Especial Olimpíadas.

PORQUE OS HOMENS CRESCEM. Jornal dos Sports, Rio de Janeiro, 3 I out I968, p. 5. Especial Olimpíadas.

RAMOS, C. H. Medalha contra o preconceito. Época, 07 de set. 1998. Disponível em: <http://epoca.globo.com/edic/l9980907/socied2.htm>. Acesso em: 03 ago. 2010.

Recebido em: 30 nov. 2010

Aprovado em: 04 abr. 20 I I

Endereço para correspondência: Rua Marcos Kawamoto, 126, Bairro Cidade Jardim, CEP 87020-5I5 Maringá - PR 